\title{
Sewer-system analysis with the aid of a geographical information system
}

\author{
SA Sinske* and HL Zietsman \\ Department of Geography and Environmental Studies, University of Stellenbosch, Private Bag X1, Matieland 7602, South Africa
}

\begin{abstract}
Geographical information system (GIS)-supported sewer-system analysis has major advantages over the use of traditional standalone sewer programs, especially with regard to establishing network topology, input of sewage contribution data, querying, displaying and mapping of results. This paper reports on the development of a GIS-supported sewer analysis software package using ArcView GIS. It supports all the stages of sewer-system analysis, viz. defining the topology of a sewer network, the specification of sewage flow contribution parameters, the allocation of sewage-contributing areas to sewer manholes, hydraulic analysis and displaying the analysis results. A sewer program has been developed for hydraulic analysis and written in Avenue, the internal programming language of ArcView. The sewer program is therefore fully integrated with ArcView, and all the functionality of ArcView is available during the sewer-system analysis. Such an integrated software package where the input data, sewer program, GIS and program results are all dynamically linked is the perfect environment for scenario management. The software package has already been successfully applied to the main sewer system of the Inner Cape Metropolitan Region (Inner CMR), as part of an M.Sc. thesis in Geography and Environmental Studies.
\end{abstract}

\section{Introduction}

The use of geographical information systems (GIS) in combination with stand-alone sewer programs to support sewer-system analysis has been known for quite some time. The integration of these systems, viz. the specially designed interfaces to transfer data from the GIS to the external program and to transfer the results back to the GIS was, however, not always perfect. The further development of such a system can also be cumbersome because of the complex link between the GIS and the external program, which must be updated all the time. Poorly integrated GIS sewer packages usually have no significant advantage over normal stand-alone sewer programs, since the data input, sewer program and program results are still separate and isolated elements. These products usually have included an optional export functionality to GIS/AutoCAD the focus is thus mainly on the sewer program and the GIS side is totally neglected. Off-the-shelf GIS systems usually have no significant built-in sewer-system analysis functionality - they have to be tailored for the specific use. It is therefore important to have a powerful internal programming language to further customise the GIS environment and to supplement existing functionality to support sewer-system analysis.

\section{Sewer-system analysis using ArcView}

ArcView, a sophisticated desktop mapping application by means of which spatial data can be visualised, explored, queried and analysed geographically (Hutchinson and Daniel, 1995; ESRI, 1996a) is a perfect platform for sewer-system analysis, because the package is well-known for its user-friendly graphical user interface (GUI) and it has a powerful object-oriented internal programming language, called Avenue (Razavi, 1995; ESRI, 1996b). With

\footnotetext{
* To whom all correspondence should be addressed.

푱 021 8865140; fax 021 8865140; e-mail: stefan@sinske.com

Received 24 July 2001; accepted in revised form 9 May 2002.
}

Avenue programming code (also referred to as scripts) the ArcView environment can further be customised and standard built-in functionality can be enhanced to support all phases in sewersystem analysis. By writing the sewer program (hydraulic engine) in Avenue, the sewer-system analysis can take place completely within the GIS and interfaces (such as DLL, DDE or common data exchange files) will therefore no longer be necessary. A better, more direct and dynamic link is therefore established between the GIS and the sewer program. All of the functionality and components of ArcView (together with the enhanced functionality) can then be utilised during the sewer-system analysis.

For the purpose of discussion, sewer-system analysis has been divided into six stages (Fig. 1), viz.:

- definition of sewer networks

- selection of sewer network

- specification of sewage flow contribution parameters

- allocation of sewage-contributing areas to sewer manholes

- hydraulic analysis

- display of the analysis results.

The newly developed sewer package has already been successfully applied to the main sewer system of the Inner Cape Metropolitan Region (Inner CMR) as part of an M.Sc. thesis in Geography and Environmental Studies (Sinske, 1998) and supports each stage of the analysis. These six stages are described in the sections that follow.

\section{Definition of sewer networks and drawing-up of attribute tables}

The location of the manholes in the sewer networks, the pipemanhole topology and attributes such as pipe slope, diameter, type of material and absolute roughness are all defined at this first stage of the analysis (Fig. 1). X, Y co-ordinates of each manhole in the sewer networks, as well as pipe invert levels, and attributes such as 


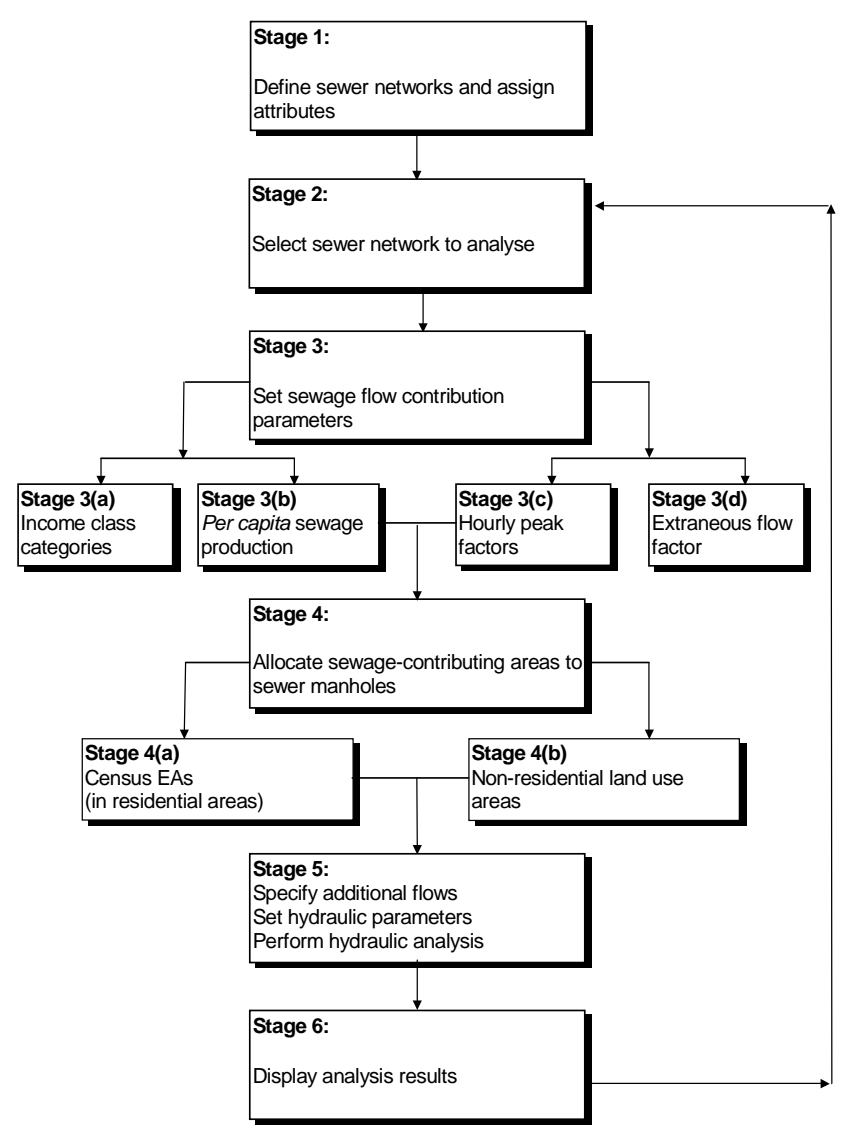

Figure 1

GIS-supported sewer-system analysis using ArcView GIS

diameter, type of material and absolute roughness, can be obtained from a GPS field survey and stored in ASCII data file format. An Avenue script has been written to convert the data contained in the ASCII data file into ArcView point and polyline themes representing the manholes and sewer pipes in the sewer networks respectively (Fig. 2). The script also generates corresponding attribute tables that contain the start-and-end manhole code of each sewer pipe in the network and this establishes the pipe-manhole topology (Fig. 2). The pipe attributes necessary for the analysis are isolated from the ASCII file and joined with the sewer network attribute table (Fig. 2). The script can build fully automatically the topology of a main sewer system with no sewer branches, as well as a sewer network with tree-like branches. The latter, however, can only be built fully automatically if the downstream manhole of each manhole in the system has been recorded in the field survey file. Without this information, the script can only build topology semiautomatically, whereby the user has to define the sewer branches by clicking on the manholes in the direction of flow. The semiautomatic graphical method for defining topology is, however, still a great improvement on the manual data entry method where the user had to enter the start-and-end manhole code of each pipe in a spreadsheet type editor.

\section{Selection of sewer network}

Once each of the sewer networks in the sewer system has been defined as described in stage one, the particular sewer network to be analysed can be selected from a customised ArcView menu system situated at the end of the standard ArcView menu (Fig. 3).

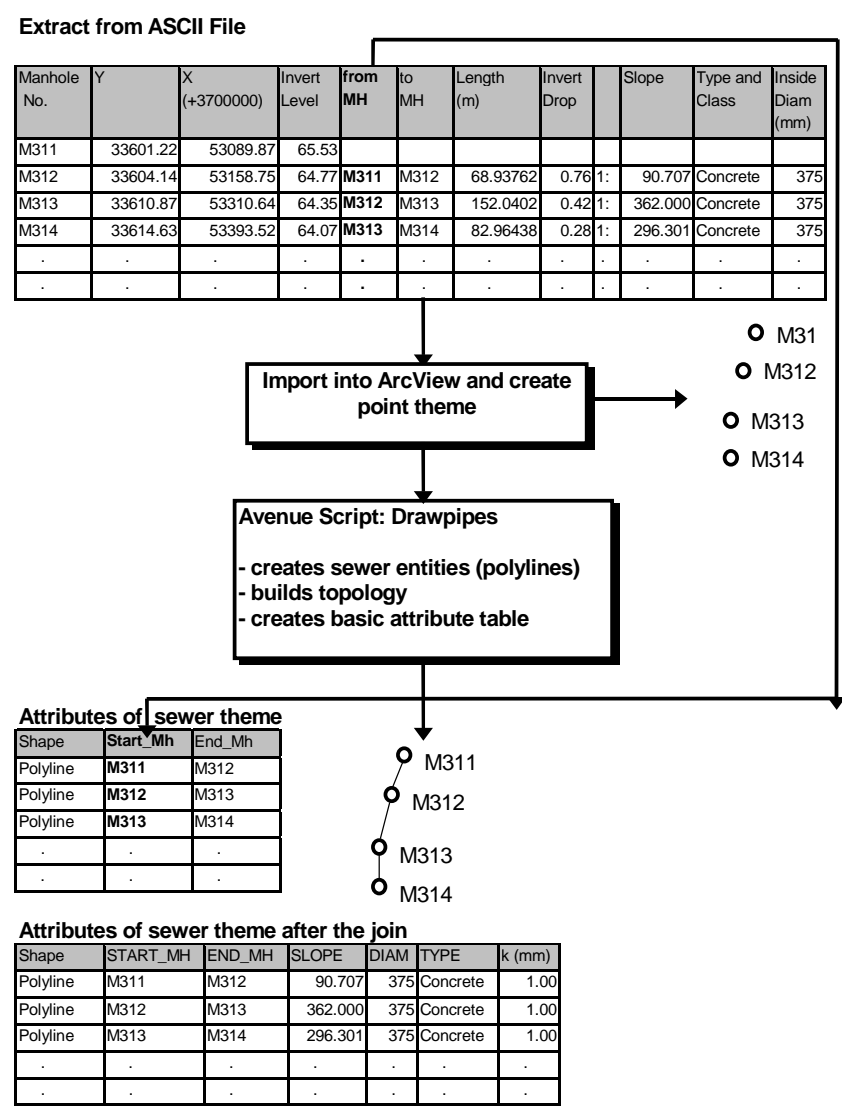

Figure 2

Definition of sewer networks and drawing-up of attribute tables

The program will then automatically zoom to the selected sewer network for specification of sewage flow contribution parameters, allocation of sewage-contributing areas to manholes and further hydraulic analyses.

\section{Specification of sewage flow contribution parameters}

Since the per capita sewage production is greatly influenced by the living standard of the population (Department of Housing, 1995), as characterised by variables such as number of people per census enumerator area (EA) and average per capita income, census data can be used to estimate sanitary sewer flows (Shamsi and Schneider, 1993). There is often also a correlation between the hourly peak factor of sewer flows and the average per capita income of a region (Van Schalkwyk, 1996). The model requires that the sewage flow contribution parameters, viz. per capita production (for residential areas) and per area unit flows (for non-residential areas), hourly peak factors and extraneous flow (wet weather) factors should be specified for each income class and land-use type of the sewer catchment areas within the study area. Appropriate income class categories can be obtained from a statistical analysis or from a geographical overlay analysis, based on the income vs. residential density relationship of the study area. The parameters can then be entered in database tables, where each record (row) contains the parameters for the catchment area of a particular sewer network in the study area. During the next stage of model specification sewage-contributing areas are allocated to manholes. 


\section{Remarks:}

- The analysis results for a pipe in the Cape Town Main Sewer are shown.

- The visible themes are: manholes of the Cape Town Main Sewer (Cpt.shp) - pipes of the Cape Town Main Sewer (Cpt_main.shp) the land-use theme (Lcl_cma2.shp)

- The selected menu item is the first menu item of the customised menu.

- The four buttons, on the far right side, just above the scale box, are four customised buttons to trigger important tasks.

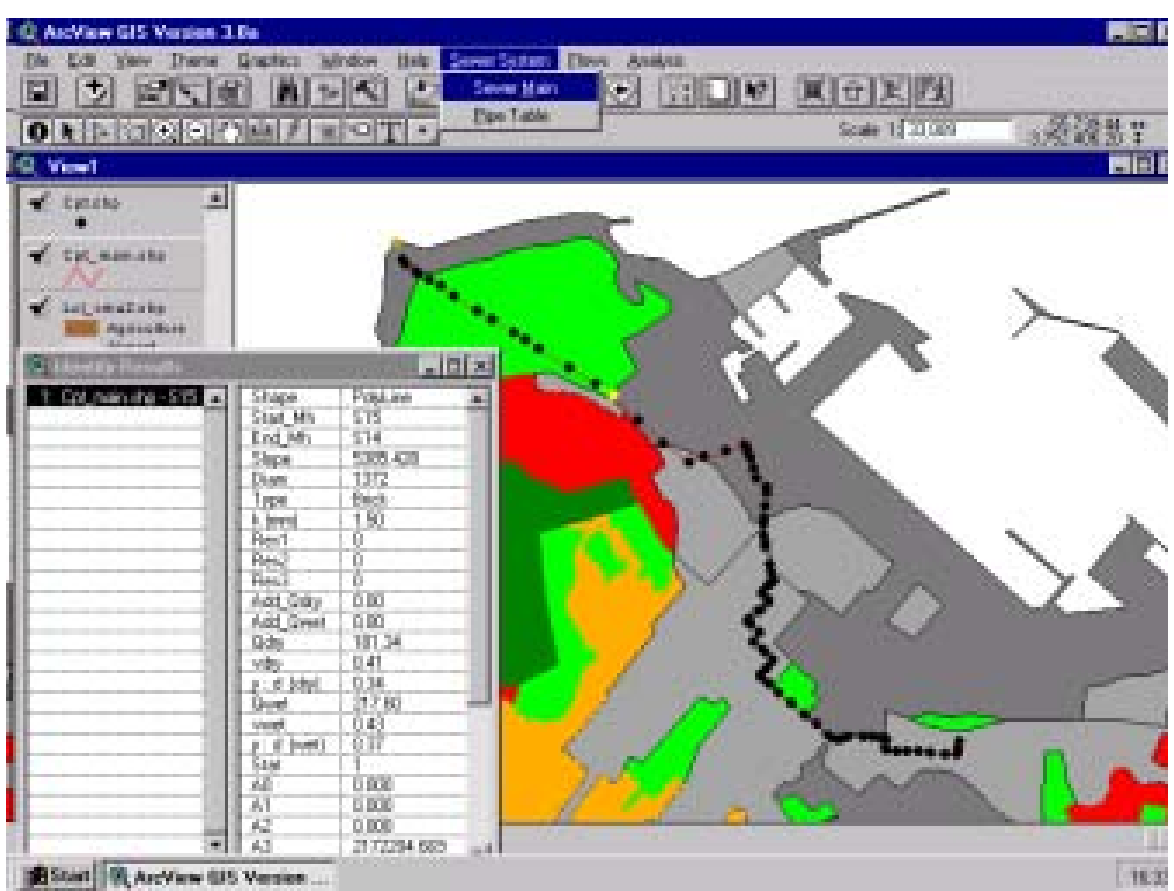

Figure 3

ArcView sewer package

\section{Allocation of sewage-contributing areas to sewer manholes}

The allocation of sewage-contributing areas to sewer manholes can be done by graphical selection in ArcView. Avenue scripts have been written to allocate census EAs to sewer manholes and to allocate non-residential areas to the sewer manholes. The script for the residential census EA allocation determines the total population of each income class in the selected set of census EAs from the census theme and writes this information in the sewer network attribute table in fields reserved for low-, middle- and high-income populations respectively (Fig. 4).

The script for the allocation of non-residential areas determines the total area of each land-use type in the selected set of land-use areas from a land-use theme and also writes this information in the sewer pipe attribute table in fields reserved for areas of different land-use types (Fig. 5). Both these scripts write cross-referenced information in two separate tables. One table lists all manhole identification codes with corresponding census EA identification codes (Fig. 4) and the other table lists manhole identification codes with corresponding land-use area identification codes (Fig. 5). This cross-referenced information is very useful for scenario management of both current and future census EA/land-use area allocation. The allocation can easily be updated for each scenario by using the cross-referenced information tables to select the census EAs/landuse areas that are currently allocated to a sewer manhole (Fig. 6) and then add/remove from the selection certain census EAs/landuse areas. Different future scenario layers can also be loaded, and the new sewage contribution parameters will be automatically fixed to the corresponding manholes, via the cross-referenced information.

Once these steps have been completed the system is virtually ready to continue with the hydraulic analysis as described in the next section.

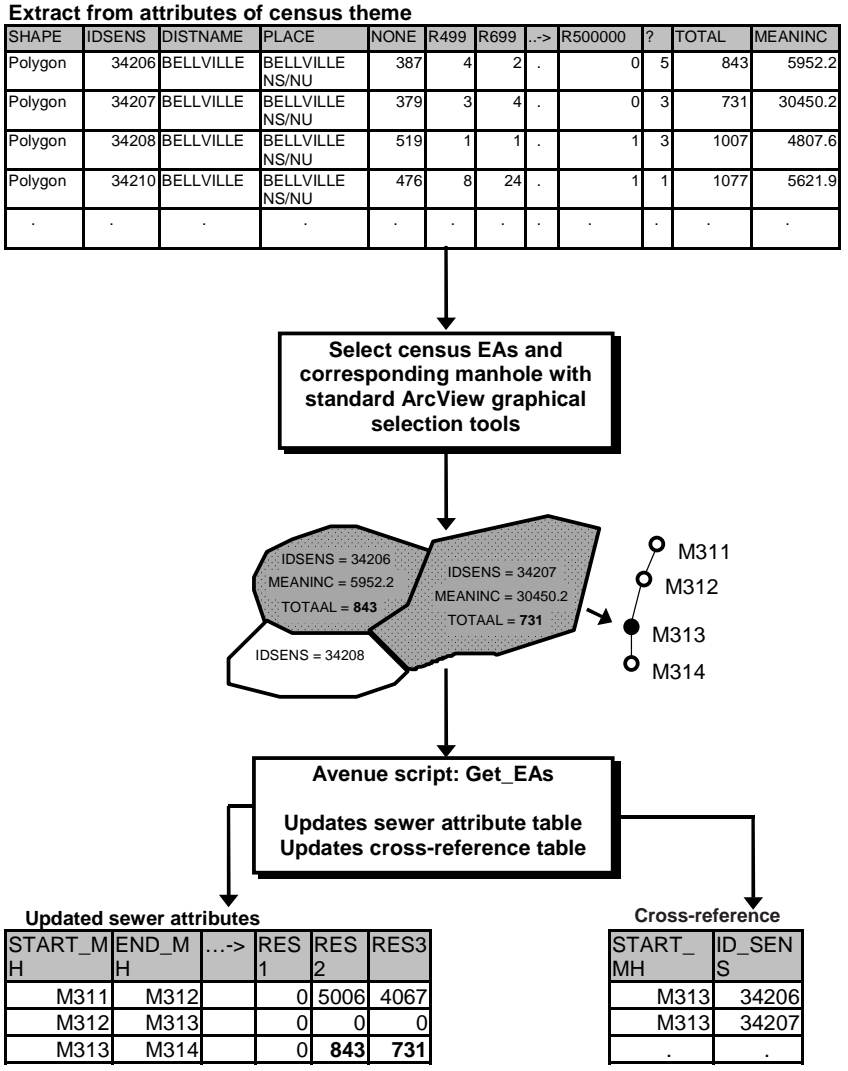

Figure 4

Allocation of census EAs to sewer manholes 
Extract from attributes of land-use theme

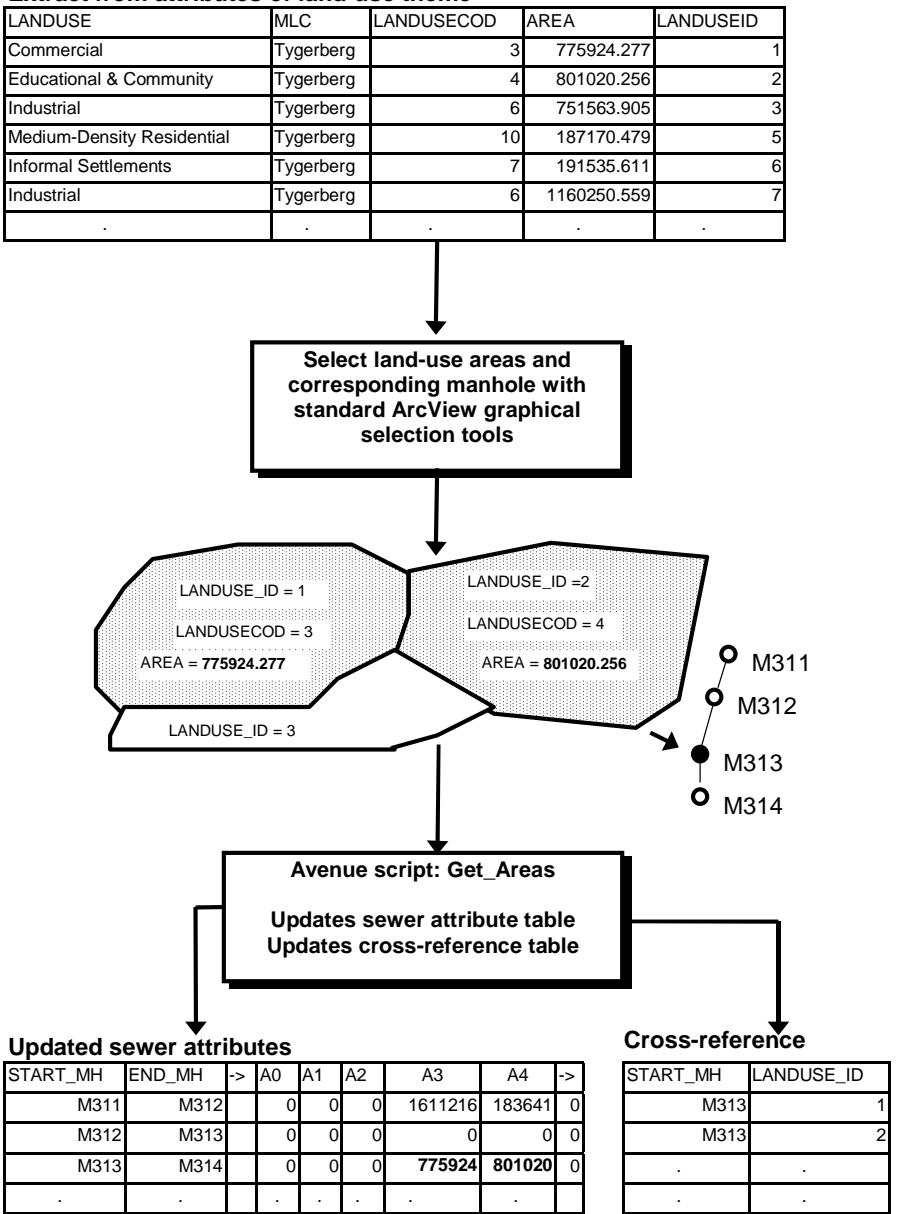

Figure 5

Allocation of land-use areas to sewer manholes

\section{Hydraulic analysis}

Additional flows and the hydraulic analysis parameters (minimum and maximum flow velocity) should be specified before executing the hydraulic analysis. An Avenue script has been written to perform the hydraulic analysis and can be run from the customised ArcView menu, mentioned earlier. The script basically does the following tasks (Fig. 7):

- Attribute data of the sewer network to be analysed are read and stored in data arrays (in Avenue, the data arrays are represented by list structures).

- The pipe directly downstream of each pipe in the sewer network is determined and the downstream pipe number is stored in a suitable data array.

- The individual flow in each pipe is calculated. The program extracts the following data from the data arrays when performing the calculations: per capita and per area production figures, the number of people in each income class, non-residential areas, as well as the hourly peak factor and extraneous flow factor.

- The flow in each pipe is routed downstream, and the accumulated flow in each pipe is calculated.

- The capacity of the pipes to carry the wet-weather flow is checked. The Darcy-Weisbach flow formula is used, in combination with the Colebrook and White roughness law (Valentin, 1995).

- If the capacity is sufficient to carry the wet-weather flow, then the dry-weather flow velocity, dry-weather flow depth ratio, wet-weather flow velocity and wet-weather flow depth ratio are calculated. The status of the dry- and wetweather flow velocity is also checked to ascertain whether they are within the allowable limit as defined by the analysis parameters which were set before execution of the analysis. The program uses a look-up table to find the $y / d$

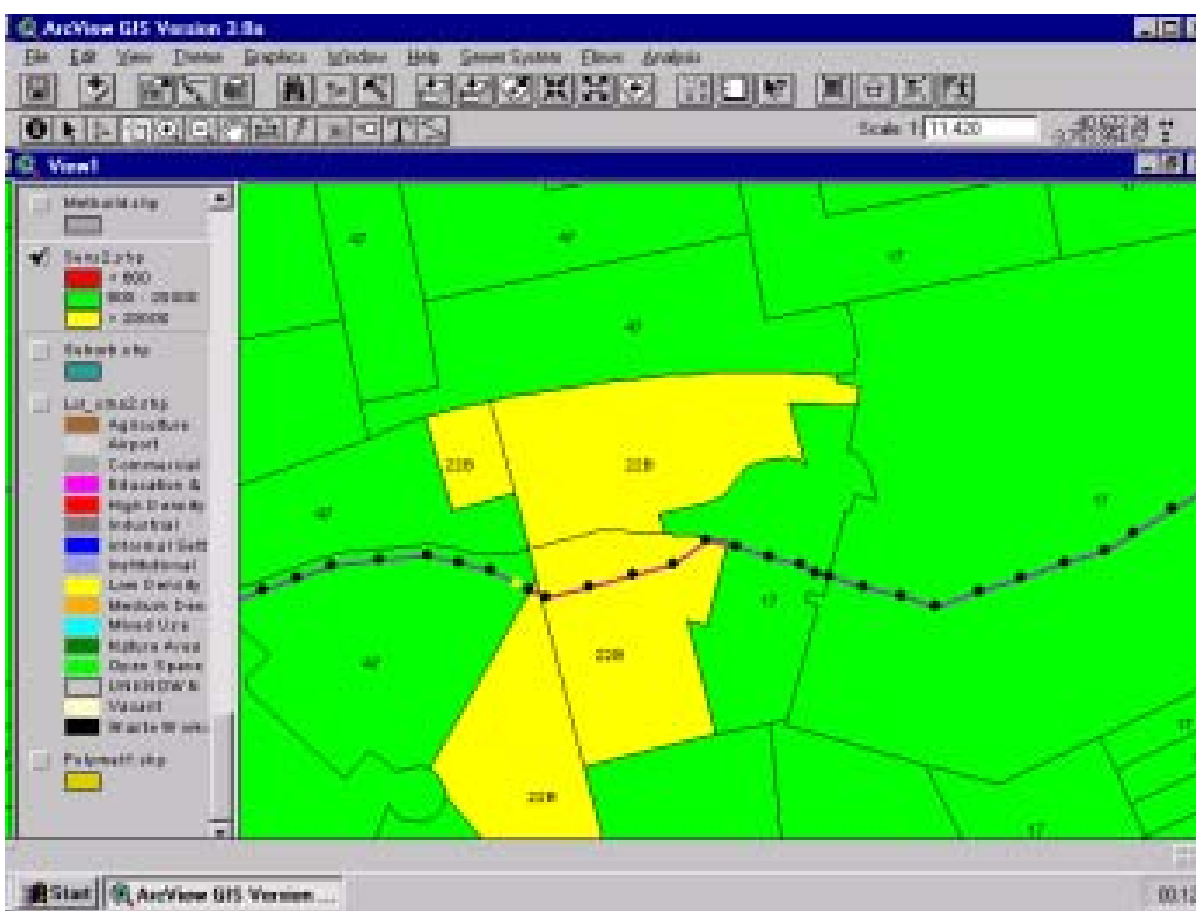

Remarks:

- By using the cross-referenced information, it is possible to label each census EA with its corresponding manhole identification code, which is stored as an attribute in the census theme attribute table.

- Subsequent queries can then also be done, as shown in the figure, where all census EAs allocated to manhole 22B were found and highlighted.

- The land-use theme, which also contains cross-referenced information, can be queried in very much the same way.

Figure 6

Mapping of manhole census EA allocation 
and $\mathrm{v} / \mathrm{v}_{\text {full }}$ ratios for a given $\mathrm{Q} / \mathrm{Q}_{\text {full }}$ ratio (Hosang and Bischof, 1993; Valentin, 1995).

- The analysis results: flow velocities, flowing depth ratios and flow status for both dry-weather and wet-weather conditions are then written to the sewer pipe attribute table.

\section{Display of analysis results}

Once the analysis results have been written to the attribute tables the results of a particular sewer pipe can be instantly obtained by clicking on it with the identify tool of ArcView (Fig. 3). By using the powerful ArcView query builder, attributes can be queried, such as to flag and display all pipes with insufficient capacity. The two tables with the cross-referenced information, discussed earlier, can be joined with the attribute tables of the census theme and land-use theme respectively, for subsequent attribute mapping. The ArcView annotation tool can then be used to produce maps that display the manhole census EA and manhole land-use area allocation (Fig. 6). Sewer pipe attributes and analysis results can be displayed in various colour- and line-thickness categories by using the ArcView thematic mapper. Finally, maps of the sewer system in context with the surrounding area can be produced with the standard ArcView layout module.

\section{Conclusions}

The integrated ArcView sewer package provides a user-friendly analysis tool where input data, sewer program and output data are dynamically linked. The major advantages of this software package over stand-alone sewer programs are:

- Pipe-manhole topology can be built very fast with the newly developed sewer package. Depending on the type of network and available field data, the topology can be built either fully automatically or semi-automatically. In both cases, the topology can be established much faster than with normal stand-alone sewer programs where start-and-end manhole codes have to be entered manually in data editors.

- The sewage contribution data, consisting of the census EAs and land-use areas, can be graphically selected with standard ArcView selection tools. When using a normal stand-alone sewer program, a data file has to be set up containing the raw sewage contribution data, such as number of people and area sizes. The data are transferred manually from paper maps to the digital file format, which is a tedious process.

- Attribute mapping and the drawing-up of final maps of the sewer network, as discussed earlier, can be performed with standard ArcView functionality. Stand-alone programs usually have only limited mapping functionality, and the program results usually have to be exported to mapping software, or to a GIS, such as ArcView. It is very inconvenient to transfer data between two software packages since the link between them is often not dynamic.

- By fully integrating the sewer program with ArcView, all of the ArcView functionality such as the selection tools, query builder, etc. and the ArcView components such as views, tables, graphs, layouts and scripts, can be utilised during the sewersystem analysis. Although stand-alone programs may have (after a very long development time) some of this functionality

\section{Figure 7}

- Reads info from sewer attribute table

- Reads info from look-up table

- Reads sewage flow contribution parameters

- Calculates flow in pipes

Checks the capacity of the pipes

Calculates flow depth ratios and velocity in pipes

- Writes analysis results to sewer attribute table

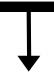

\begin{tabular}{|l|l|l|l|l|l|l|}
\hline y & vdry & y:d (dry) & Qwet & Vwet & y:d (wet) & STAT \\
\hline
\end{tabular}

\begin{tabular}{|l|r|r|r|r|r|r|r|r|r|r|r|}
\hline M312 & 90.707 & 375 &. & 56.62 & 1.55 & 0.37 & 67.95 & 1.64 & 0.41 & 0 \\
\hline M313 & 362.000 & 375 &. & 56.62 & 0.92 & 0.55 & 67.95 & 0.96 & 0.62 & 0 \\
\hline M314 & 296.301 & 375 &. & 71.82 & 1.05 & 0.60 & 86.18 & 1.08 & 0.68 & 0 \\
\hline. &. &. &. &. &. &. &. &. &. & \\
\hline
\end{tabular}

\begin{tabular}{l|l|l|}
\hline Hydraulic analysis & 3 & Pump vel OK \\
\cline { 2 - 3 } & 4 & Pump vel < vmin! \\
\hline 5 & Pump vel > vmax! \\
\hline
\end{tabular}

incorporated, they will, however, still not be so effective and reliable as the built-in ArcView tools, which have been developed by a large organisation (ESRI) and tested by an extensive user base.

The sewer software package, which can already do scenario management ("what if" analyses), should be further developed to become a powerful planning tool for the design of new sewer systems. In the new release of ArcView (part of the ArcGIS 8 system), the use of Avenue scripting has been replaced by the internal programming language Visual Basic for Applications (VBA) (ESRI, 2001). A new VBA version of the sewer software package, based on the principles presented in this paper, is already in the final stages of development and will soon be released.

\section{References}

DEPARTMENT OF HOUSING (1995) Guidelines for the Provision of Engineering Services and Amenities in Residential Township Development. CSIR, Division of Building Technology, Pretoria.

ESRI (1996a) Using ArcView. ESRI, Redlands Ca.

ESRI (1996b) Using Avenue. ESRI, Redlands Ca.

ESRI (2001) What is ArcGIS? ESRI, Redlands Ca.

HOSANG G and BISCHOF W (1993) Abwassertechnik. Teubner, Stuttgart.

HUTCHINSON S and DANIEL L (1995) Inside ArcView. OnWord Press, Santa Fe.

RAZAVI AH (1995) AcrView Developer's Guide. OnWord Press, Santa Fe.

SHAMSI UM and SCHNEIDER AA (1993) GIS forecasts sewer flows. GIS World 6 (3) 60-64. 
SINSKE SA (1998) Analysis of the Main Sewer System of the Inner Cape Metropolitan Region with the Aid of a Geographical Information System. M.Sc. (Geogr. and Environ. Studies) Thesis, Univ. of Stellenbosch, Stellenbosch.

VALENTIN F (1995) Abwasserableitung. In: ATV-Handbuch: Planung der Kanalisation (4 ${ }^{\text {th }}$ edn.). Ernst \& Sohn, Berlin. 447-466.
VAN SCHALKWYK A (1996) Guidelines for the Estimation of Domestic Water Demand of Developing Communities in the Northern Transvaal. Water Research Commission Report No. 480/1/96. 